\title{
Neighbor Discovery in ASN
}

\author{
M. Jasmin, S. Philomina, S.Arulselvi, Balaji S.
}

\begin{abstract}
Generally the hubs that are placed in a system of sensors remain in static condition. The availability condition of these hubs are also likely to change due to various conditions such as remote location, change of power due to transmitting procedure and also due to the lack of coordination between the hubs which are placed adjacently. The system should continuously track its components. This process should takes place without any gap. This work deals with nonstop tracking of the adjacent component present in the framework. This procedure should utilize power to the minimum level thereby upgrading the performance metrics.
\end{abstract}

Keywords: Hub, ASN, framework.

\section{INTRODUCTION}

A sensor system might contain countless sensor hubs that are conveyed at some investigated site. In extensive regions, such a system typically has a lattice structure. For this situation, a percentage of the sensor hubs go about as switches, sending messages starting with one of their neighbors then onto the next. The hubs are designed to turn their correspondence equipment on and off to minimize vitality utilization.

Here the hubs are in the random points when we consider the whole system.Their main job is to find the adjacent element and to do the necessary updates. This helps to build up an efficient communication. The activities of the hub which are considered as their neighbours are monitored with minimal utilization of the resources.

\section{SYSTEM ANALYSIS}

\section{EXISTING SYSTEM}

Generally the located neighbours are identified without any particular condition. The environmental structure is not at all considered. This prevailed condition degrades the performance as it is not able to do its allotted work properly This in turn will result in a meshy environment.

\section{PROPOSED SYSTEM}

The hazards in the prevailing system is rapidly eradicated by continuous tracking of the associated neighbours. The ceaseless tracking helps in analyzing each and every component deeply. The main ideas is to reduce the utilization of power to a greater extent. This factor is achieved at a minimal time. The set up framed helps to attain this to improve the efficiency.

\section{SYSTEM ARCHITECTURE}

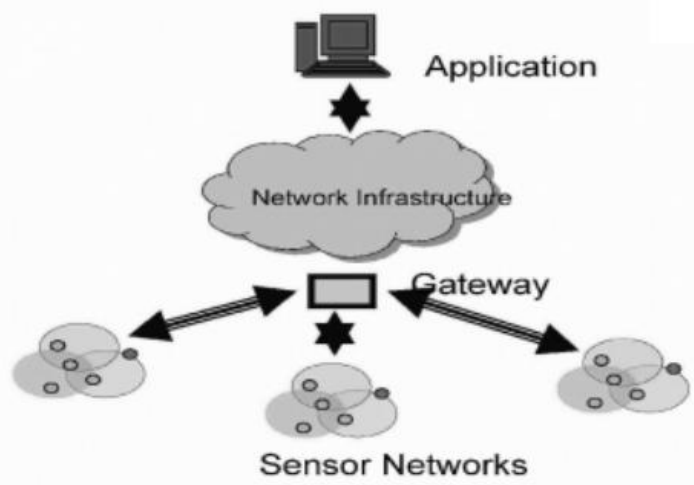

NETWORK ARCHITECTURE:

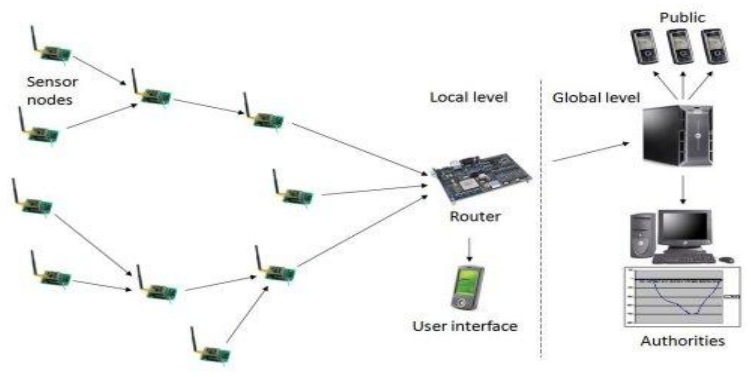

\section{DATA FLOW DIAGRAM}

DFD is a graphical representation of the activities that are taking place. The method tries to convey the policy and principle in an understandable graphical format. Once the adapted method is understood the necessary data is created and effectively used by this framed system.

Published By: ucation and Research Chennai, Tamilnadu, Email: rifriz@gmail.com education and Research Chennai, Tamilnadu. Email:

S.Arulselvi, Assistant professor /ECE , Bharath university of Higher education and Research Chennai, Tamilnadu. Email: arulselvi2003@gmail.com

Balaji S, Assistant professor /ECE, Bharath university of Higher education and Research Chennai, Tamilnadu. Email: bala.sripathy@gmail.com

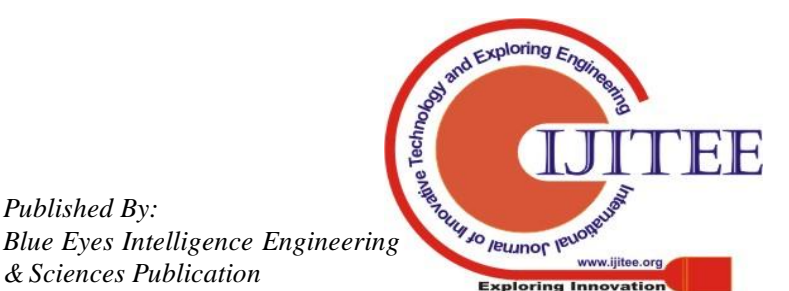




\section{Neighbor Discovery in ASN}

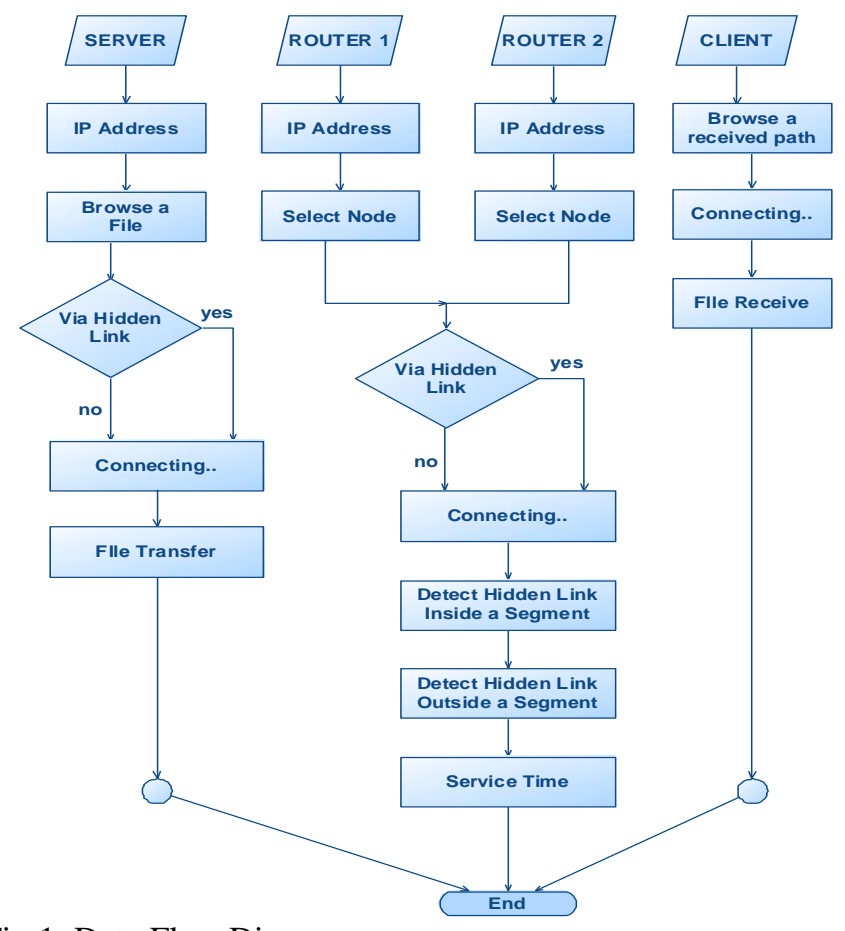

Fig 1. Data Flow Diagram

\section{SYSTEM IMPLEMENTATION}

The real success of any task is achieved when it is put into execution in the real world. If not it will remain as an imaginary thing. Executing successfully the developed concept causes the victory of the concerned system.

To accomplish the above mentioned activity strategic planning, continuous supervision and the underlying demerits should be strictly taken into consideration. By doing so the new techniques framed can be successfully deployed in the framed system

\section{RESULTS}

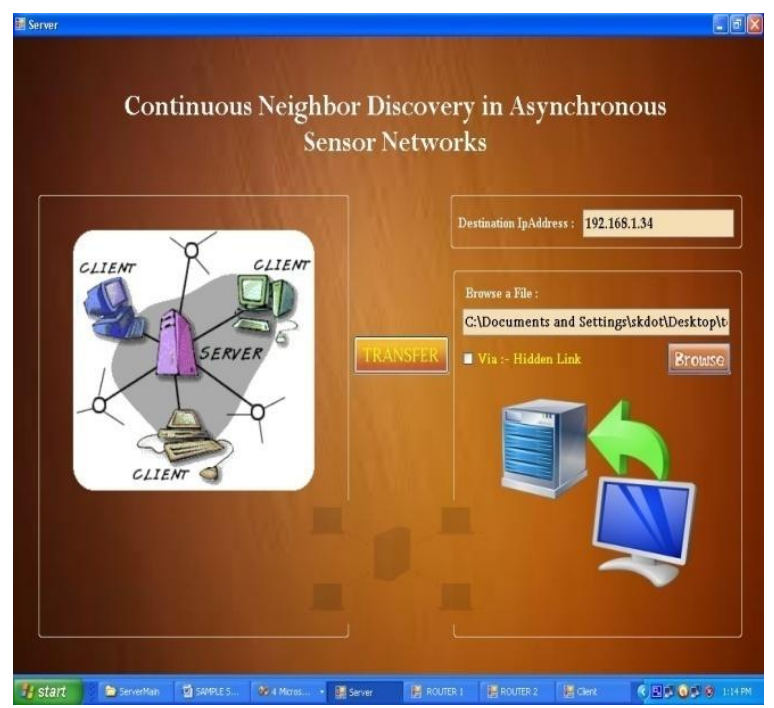

Fig 2 Server Interface

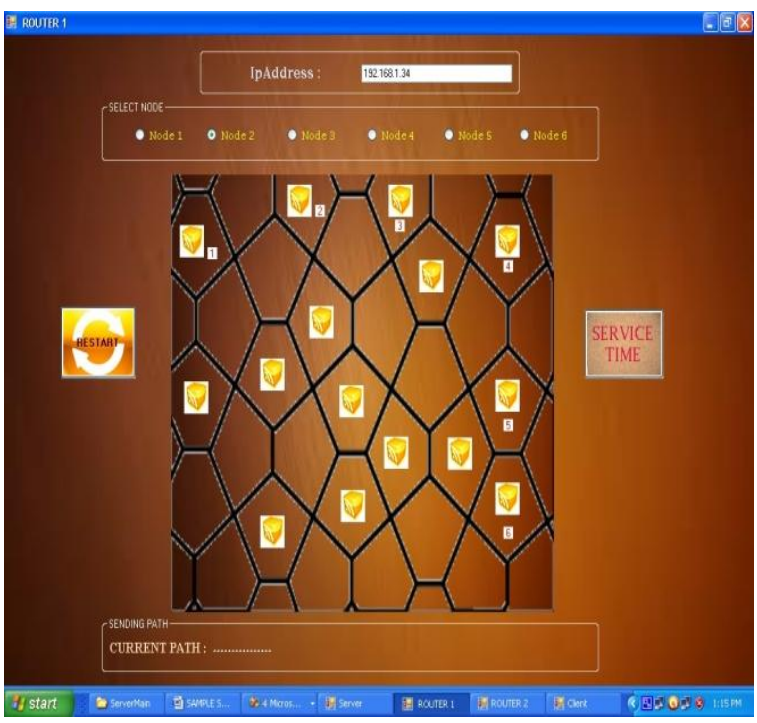

Fig 3 Router Interface

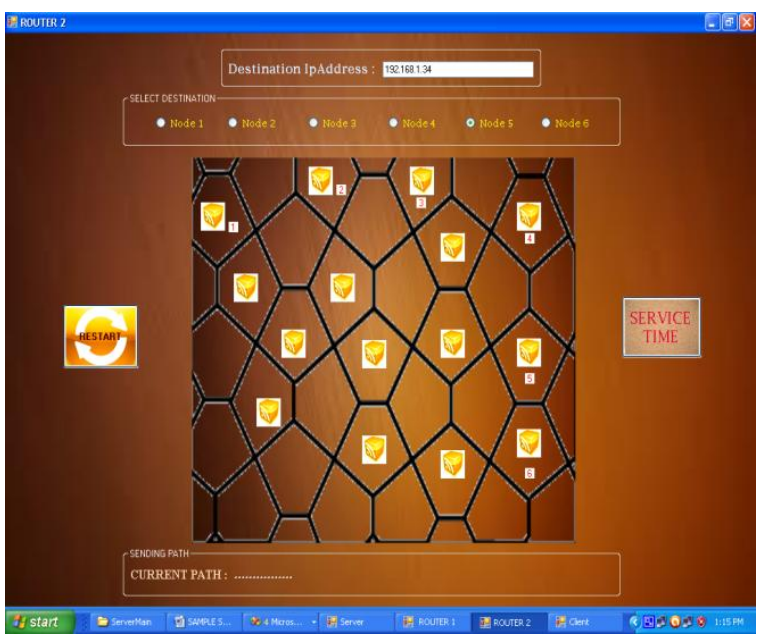

Fig 4 Selection of Destination Nodes

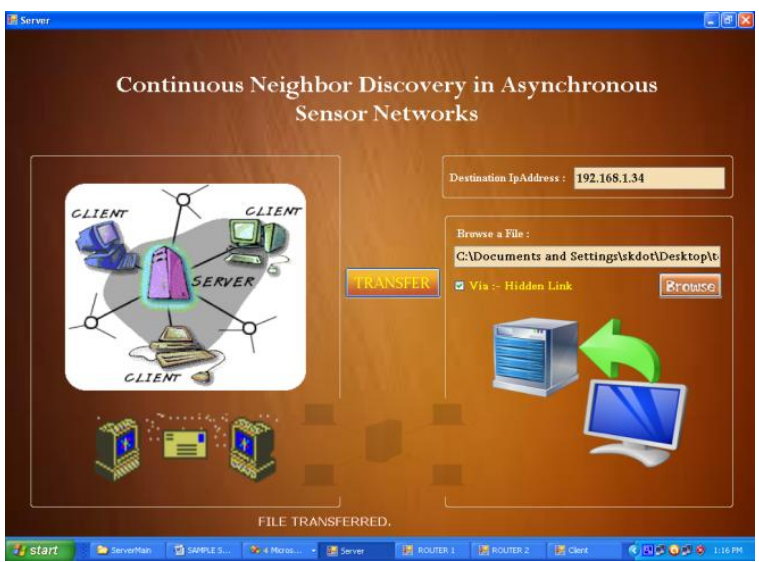

Fig 5 File Transferred Path 


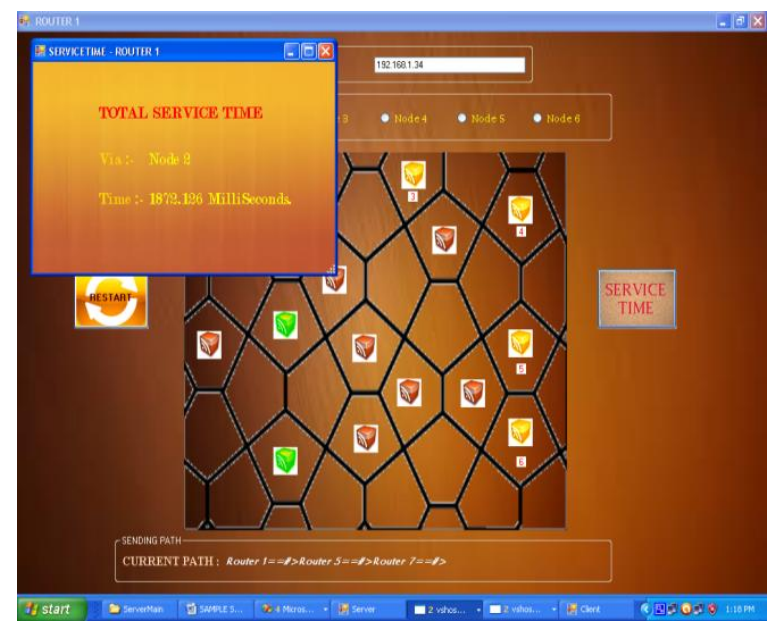

Fig 6 Node Service Time

\section{CONCLUSION}

We uncovered another issue in remote detector systems, alluded to as progressing consistent neighbor system. We tend to contend that persistent neighbor revelation is important no matter the actual fact that the detector hubs area unit remain static. On the off likelihood that he hubs in associated portion collaborate on this trip, the shrouded hubs area unit ensured to be distinguished within a particular chance $P$ and a particular fundamental measure $\mathrm{T}$, with lessened used on the invention. We reveal that our arrange functions perform laudably if every hub is related to its adjacent neighbors. We tend to then introduce a persistent neighbor revelation calculation that decides the return. We reproduced a detector system to dissect our calculations and worked it systematically within the zone.

\section{REFERENCES}

1. Abraham Silberschatz 'Operating System Concepts'.December 14, 2004.

2. Behrouz A Forouzan 'Data Communications and Networking' August 13, 2003 .

3. Imar Spaanjaars 'Beginning ASP.NET 4 in C\# and VB' July 23, 2010.

4. James F. Kurose 'Computer Networking: A Top-Down Approach'April 2, 2007

5. Jesse Liberty, Dan Maharry, Dan Hurwitz'Programming ASP.NET 3.5'November 3, 2008.

6. Matthew MacDonald'Beginning ASP.NET 3.5 in C\# '2008

7. Stephen Walther'Asp.Net 4 Unleashed' October 24, 2010.

8. Continuous Neighbor Discovery In Asynchronous Sensor Networks IEEE /Acm Transactions On Networking, Vol. 19, No. 1, Feb 2011.

9. R. Madan and S. Lall, .An energy-optimal algorithm for neighbor discovery in wireless sensor networks,. Mob. Netw. Appl., vol. 11, no. 3, pp. 317.326, 2006.

\section{AUTHORS PROFILE}

M.Jasmin, Assistant professor /ECE, Bharath university of Higher education and Research Chennai,India

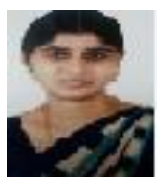

S.Arulselvi ,Assistant professor /ECE

, Bharath university of Higher

education and Research

Chennai,India

Balaji S., Assistant Professor , ECE, Bharath Institute of Higher Education and Research,Chennai,India 